o irmão mais velho lhe faz conhecer desde 1905, são os contatos com o movimento socialista turinês nos anos da Faculdade que ele cursou em Turim. Brilhante aluno do curso de Letras, não consegue todavia manter um ritmo constante de estudo curricular devido às instáveis condições de saúde e a incipiente atividade política.

Colaborador dos cotidianos "Il grido del popolo" e "Avanti", mantém conferências nos círculos operários, experiência essa que lhe faz sentir a necessidade de integrar a ação política e econômica com um órgão de atividade cultural, e lhe sugere a criação de uma associação proletária de cultura. Sempre com o intuito de renovar ideológica e culturalmente o movimento socialista, funda em 1919 a revista 'L'Ordine Nuovo" que estará à frente do movimento operário pelas propostas inovadoras e como fonte de informação dos movimentos operários internacionais, das vozes mais vivas da política e da revolução no campo da cultura. São publicados textos de Bela Kun, Zinov'ev, Lenin, Barbusse, Lunatcharsky, Romain Rolland, Eastman, Martinet, Gorki.

A atividade política o afasta da linha do partido socialista até que, em 1921, é chamado a participar do Comitê central do então recém constituído Partido Comunista da Itália. Começa um período de atividade intensíssima, de novas formulações políticas e novos contatos. Gramsci é designado para manter os contatos com o Comitê executivo da Internacional Comunista e com os outros partidos comunistas européus. Em política interna adota a linha da aliança entre as camadas mais pobres da classe operária do Norte e as massas rurais do Sul.

Em 1924 é eleito deputado e em 1926 é preso pela polícia fascista. Durante o processo de 28 de maio de 1928 que o condenou a 17 anos de reclusão, o promotor público, Michele Isgrò, afirma:
"Por vinte anos temos que impedir a este cérebro de funcionar". Os anos de prisão são duríssimos também pela grave doença que o obriga a longos períodos de imobilidade quase absoluta. Graças à dedicação de Tatiana Schucht e ao empenho do economista Piero Sraffa, Gramsci obtém a permissão de estudar e escrever. São os amigos que lhe fornecem os materiais necessários.

Em 1933, em Paris, se constitui um comitê para a libertação de Gramsci e das vítimas do fascismo, mas Gramsci deixará a prisão em 1934 apenas para ser transferido para uma clínica. Em 1937 obtém a liberdade e se propõe a se restabelecer na ilha natal. Morre antes de realizar o projeto na tarde do 25 de abril de 1937.

\section{A Revolução Burguesa}

Fernandes, Florestan

\section{Zahar Editores, 1975}

\section{Paulo Silveira}

Os comentários surgidos até agora sobre este último livro de Florestan Fernandes, independentemente de seu teor crítico (e, portanto, político) têm concordado com a dificuldade da leitura do texto. Por que $A$ Revolução Burguesa no Brasil é um texto difícil?

Esta dificuldade provém principalmente dos níveis em que trabalha o Autor: o da história e o da estrutura. Confundi-los não só acarreta dificuldades de leitura, mas, o que é pior, interpretações errôneas.

Com efeito, a arquitetura profunda deste trabalho está fundada na distinção que o Autor faz entre história e estrutura. Elas são como que os pilares que sustentam e que fundam todo o discurso. Esta importância requer que se medite um pouco sobre essa distinção.

Por estrutura Florestan Fernandes entende a configuração mais profunda 
da sociedade brasileira, a um tempo capitalista - e como tal implicando nas contradições fundamentais do MPC e dependente - nesse caso imbricada na maneira pela qual se expande o capitalismo, em particular, com os laços que se estendem necessariamente a partir das nações capitalistas hegemônicas. Mas pensar a estrutura da sociedade brasileira apenas nestes termos é ainda permanecer num nível muito abstrato. De um lado este caráter capitalista implicando na contradição entre as classes sociais, e de outro, o caráter dependente suscitando as formas de dominação externa, que frequentemente são denominadas abstratamente de imperialismo. De outro ângulo, seria tentar resolver por aglutinação, a polêmica que se tem travado sobre a abordagem mais adequada — teórica e politicamente — à análise das sociedades capitalistas dependentes ${ }^{(1)}$.

É precisamente no aprofundamento de sua concepção da estrutura da sociedade brasileira que se encontra uma das contribuições mais importantes de Florestan Fernandes nesse texto. Para além daquelas configurações mais abstratas já apontadas, o Autor nos acena à dupla articulação econômica que caracteriza a estrutura da sociedade brasileira: interna e externa. Articulação interna: entre os diferentes setores econômicos internos, e suas distintas formas de produção e, por conseguinte, de exploração do trabalho, que implicam em formas relativas de subdesenvolvimento. Articulação externa: entre a economia brasileira, e particularmente alguns setores desta, e as economias centrais, o que supõe certas modalidades de dependência.

Tomadas isoladamente cada uma dessas articulações, não se percebe certamente a novidade do texto. Essa arti-

(1) Ver, por exemplo, o debate entre Francisco C. Weffort e Fernando $\mathrm{H}$. Cardoso, Estudos CEBRAP - 1 . culação interna, se não foi suficientemente explorada, foi pelo menos indicada, em relação às sociedades latino-americanas, a mais de dez anos por Stavenhagen nas "Sete Teses Equivocadas sobre a América Latina", na forma do que ele denominou de "colonialismo interno" e que na oportunidade era uma crítica às teorias dualistas. A articulação externa, que define o caráter dependente das sociedades latino-americanas, talvez tenha tido a sua primeira expressão mais acabada nos textos de Gunder Frank, alguns dos quais também já com mais de dez anos.

A novidade do texto, então, não é a mera referência a essas articulações, mas a forma pela qual elas se concretizam na sociedade brasileira. O Autor nos mostra não só como se concretizam essas articulações — interna e externa —, mas também - e aí talvez resida o ponto mais importante - como elas se articulam entre si. Isto é, para além de qualquer tipo de relação mecânica entre o interno e o externo, ele procura demonstrar dialeticamente que essa dupla articulação faz parte de uma mesma unidade: a estrutura da sociedade brasileira. O externo — a dependência - não é tomado como uma referência para se compreender o interno, ele ganha poder explicativo quando é pensado como fazendo parte mesmo da estrutura interna, ou seja, o "externo" é um determinante essencial das condições internas.

Não se trata de mera retórica, esta posição suscita problemas políticos muito sérios. O externo não é pensado como um "enclave" que possa ser extirpado como um quisto, por exemplo, através de medidas políticas de tipo nacionalista. Ao contrário, como componente mesmo da estrutura interna, ele só pode ser suprimido com a própria supressão desta estrutura. Isto ao mesmo tempo põe fim ao mito da autonomia de uma burguesia nacional, que tem servido 
historicamente a uma série de alianças políticas.

Se bem que este nível estrutural seja fundamental à análise da sociedade brasileira - e aqui começam as dificuldades -, restringir-se a ele significa permanecer ainda num patamar bastante abstrato. E é neste ponto que entra a análise propriamente histórica, isto é, de que maneira os agentes sociais classes, frações de classe etc., - vivenciam aquela condição estrutural; de que maneira esta estrutura é fortalecida, é vitalizada, ou, ao contrário é solapada, é subvertida. O Autor nos mostra, contudo, que a rigor apanas a primeira dessas alternativas concretizou-se como história, a ponto do texto parecer uma história da burguesia (daí também $A$ Revolução Burguesa no Brasil). Por exemplo, referindo se a etapa competitiva do capitalismo dependente: "Assim, mantida a dupla articulação, a alta burguesia e a pequena burguesia 'fazem história'. Mas fazem uma história de circuito fechado ou, em outras palavras, a história que começa e termina no capitalismo competitivo dependente" ( $p$. 250).

As dificuldades. O Autor trabalha $o$ tempo todo com esses dois níveis - o estrutural e o histórico - , isto é, mantendo viva a estrutura complexa com dupla articulação do capitalismo dependente e, ao mesmo tempo, mostrando como ela se concretiza historicamente. A primeira funciona como uma determinação profunda que enlaça as classes sociais e suas relações; o segundo nível — o histórico — diz respeito à realização efetiva das relações de classe. Não se trata, como poderia pensar, de duas "histórias": uma história lenta e profunda das estruturas e uma história superficial das relações de classe (o leitor que procurar encontrar no texto uma história "acontecimental" certamente vai decepcionar-se). Por outro lado, não há também similitude com certa concepção estruturalista, através da qual as classes sociais e as relações de classe são consideradas com meros suportes das estruturas. Ao contrário, Florestan Fernandes não se permite afastar, em nenhum momento, do caráter contraditório dessa estrutura, o que alija completamente a possibilidade de uma leitura que considere a estrutura como determinante $\mathrm{e}$ as relações de classe como determinadas (perspectiva que acaba esfumando a contradição estrutural). Sim, a estrutura tem também, para o Autor, um caráter determinante, mas que nada tem a ver com uma relação linear de causa e efeito. A determinação estrutural abre um campo de possibilidades, de alternativas (de acomodação, competição e conflito) que se põem e se realizam historicamente, dependendo em cada momento do peso relativo e da atuação efetiva das forças sociais em presença (classes sociais, frações de classe, categorias sociais etc.). Assim se a estrutura é determinante à história (e a sua inteligibilidade), a história é o lugar privilegiado da análise, pois é nela que essa estrutura se realiza efetivamente, permanecendo, contudo, sempre como possibilidade histórica a sua não realização, ou seja, a ruptura dessa mesma estrutura. É por esta razão que, em vários momentos do texto, Florestan Fernandes refere-se às alternativas que foram postas historicamente, sejam aquelas que foram frustradas ou aquelas que não foram nem mesmo pressentidas. Digressões que, como já deve ter ficado claro, não se relacionam com a saturação ou não de um modelo típico-ideal.

Como vimos, então, o Autor não teve outra alternativa senão enfrentar esta dificuldade de operar concomitantemente com os dois níveis: estrutural e histórico. Se se restringisse ao primeiro, estaria condenado a uma análise por demais abstrata. Se optasse apenas pelo segundo, perderia a condição de inteligibilida- 
de dos processos históricos efetivos e teria atingido as raias de uma história fatual. Desse modo, apesar de ser em certos pontos difícil. A Revolução Burgueșa no Brasil é uma das contribuições mais importantes que tem aparecido sobre a história da sociedade brasileira e que certamente deve servir de marco obrigatório a quem queira refletir não só sobre a nossa sociedade, como, de resto, sobre as sociedades vinculadas ao capitalismo dependente.

\section{NOTÍCIAS}

a) Curso de Pós-Graduação em Filosofia e Teoria das Ciências Humanas

Vem sendo organizado, desde 1974 e destina-se à formação de mestres nesta área. Deverá ser instalado no período de 1977, assim que for aprovado pela Comissão Central de Pós-Graduação da Universidade Estadual Paulista "Júlio de Mesquita Filho". A Faculdade de Filosofia, Ciências e Letras de Assis será a sede administrativa do Curso. Seu corpo docente está formado por doutores e docentes livres das Faculdades de Assis, de Araraquara e de Marília, num total de 12 pesquisadores, se responsabilizando pela orientação dos alunos. Serão convidados também alguns especialistas nacionais ou estrangeiros, para colaborar na execução dos programas. Para inscrição no Curso o candidato deverá possuir diploma de Curso Superior em Filosofia ou áreas afins, expedido por instituição de ensino oficialmente reconhecida. Número de vagas: 60 (a ser preenchido em três anos). São as seguintes as áreas de concentração: História da Filosofia (Antiga, Medieval, Moderna, Contemporânnea); Filosofia das Ciências Humanas (Filosofia da História, Teoria das Ciências Humanas); Ética e Filosofia Política (Filosofia e Mitologias, Teoria das Ideologias, Ideologia e Formação Social); Estética e Filosofia da Arte; Epistemologia e Semiologia; Filosofia e Educação. O Con- selho do Curso está formado pelos Doutores Wílcon Jóia Pereira (Cooordenador), Ubaldo Puppi e Péricles Trevisan.

\section{b) I Jornada de Estudos de Filosofia e Teoria das Ciências Humanas}

Realizou-se nos dias 30 de novembro e 19 de dezembro de 1975 na Faculdade de Filosofia de Assis a I Jornada de Estudos de Filosofia e Ciências Humanas reunindo professores de várias unidades da UNESP e promovido pelo Conselho do Curso de Pós-Graduação em Filosofia. Os debates se desenvolveram em torno das relações entre Filosofia e Teoria das Ciências Humanas, com a participação especial da professora Maria Sylvia de Carvalho Franco e do professor Gabriel Cohn, ambos da Universidade de São Paulo.

\section{c) Cursos de especialização:}

Promovido pelo Departamento de Filosofia, ministrou-se durante $\mathrm{o}$ ano escolar de 1975 um curso sob o tema Cinema: Linguagem e Ideologia. Professores do próprio Departamento bem como alguns convidados (críticos e especialistas em Cinema) orientaram o trabalho e a pesquisa de alunos graduados em Filosofia, Letras, Psicologia e Ciências Sociais.

Através de dois de seus docentes, o Departamento de Filosofia foi o co-responsável, juntamente com o Departa- 